\title{
The influence of extraframework aluminum on H-FAU catalyzed cracking of light alkanes
}

\author{
T.F. Narbeshuber, A. Brait, K. Seshan, J.A. Lercher * \\ Christian Doppler Laboratory for Heterogeneous Catalysis, Faculty of Chemical Technology, University of \\ Twente P.O., Box 217, 7500 AE Enschede, The Netherlands
}

\begin{abstract}
The conversion of light linear and branched alkanes on two faujasite samples containing different concentrations of free Brønsted acid sites and extraframework alumina (EFAL) was studied between $733 \mathrm{~K}$ and $813 \mathrm{~K}$. Protolytic cracking and bimolecular hydride transfer proceeded solely on Brønsted acid sites. For cracking of $n$-alkanes, the variation of the concentration of extraframework aluminum did not affect the catalytic activity per accessible Brønsted acid site. The activity to dehydrogenation is enhanced in the presence of EFAL and, unlike protolytic cracking, it decreased with time on stream. At high conversions relatively high concentrations of olefins change the selectivity and decrease the turnover frequencies. Compared to $n$-alkanes, the catalytic activity to convert iso-alkanes is enhanced in the presence of extralattice alumina.
\end{abstract}

\section{Introduction}

Both, Brønsted and Lewis acid sites are usually found in industrial zeolite catalysts [1-5]. The catalytic activity and selectivity of these zeolites depend upon the type, the strength and the concentration of these sites. The individual role of these three parameters for rate and selectivity in hydrocarbon conversion has been vividly debated [1-19].

Haag et al. [6,7] reported the activity for n-hexane cracking on H-ZSM5 to be directly proportional to the concentration of tetrahedrally coordinated aluminum (i.e., to the concentration of the Brønsted acid sites). This indicates identical properties of the catalytically active sites in H-ZSM5. The acid sites in H-ZSM5 (and other protonic forms of high silica zeolites), however, are unique as they

\footnotetext{
${ }^{*}$ Corresponding author. Fax: $+31-53-4894683$.
} 
are so remote from each other that mutual influences are minimal. However, zeolites with higher aluminum concentration in the lattice, such as H-FAU and $\mathrm{H}-\mathrm{MOR}$, have aluminum lattice atoms as next nearest neighbours, which supposedly decrease the strength of the individual sites [10-12,14].

Mild steaming of H-ZSM5 was reported to increase the catalytic activity for cracking of $n$-hexane $[13,17,18]$. The catalytic activity of acid sites generated by mild steaming is claimed to be approximately 45 times higher than that of normal Brønsted sites [13]. It was suggested that the high catalytic activity was due to synergistic effects between the SiOHAl groups in the lattice and the aluminum moieties generated by partial dealumination.

In contrast, more severe steaming of zeolites results in a high degree of dealumination and in the formation of extraframework aluminum oxide species, which are not found to induce higher catalytic activity. However, a comparison between chemically dealuminated (low concentration of extraframework species) and steamed zeolites showed that the latter were considerably more active for hydrocarbon cracking, when the zeolites were dealuminated to the same $\mathrm{Al}$ content $[12,18]$. This suggests that extraframework aluminum oxide in the zeolite pores may play a significant role in the catalytic conversion of hydrocarbons.

Potentially, the extraframework alumina could have various effects on the catalytic activity: (i) The extraframework species self could be catalytically active. (ii) Extraframework species could interact with bridging hydroxyl groups and enhance their acid strength. (iii) Positively charged (cationic) extraframework aluminum oxide clusters could act as cations to neutralize Brønsted acid sites. (iv) Extraframework aluminum oxides may block the accessibility of fractions of the zeolite pores.

The present communication adresses the role of such extraframework aluminas using two faujasite samples, differing in the concentration of Brønsted acid sites and extraframework aluminum, as model catalysts for the catalytic conversion of light alkanes.

\section{Experimental}

\subsection{Samples}

The physicochemical properties of the two faujasite catalysts are compiled in Table 1. The parent material (HY-P, obtained from Degussa) contained large quantities of extraframework aluminum. This sample was treated with $0.1 \mathrm{~N}$ ammonium hydroxide solution to remove a major fraction of the extraframework alumina [20]. The modified material (HY-M) had approximately twice the concentration of accessible strong Brønsted acid sites and approximately half the concentration of extraframework aluminum species as the parent faujasite HY-P, 
Table 1

Physicochemical characterisation (values taken from Ref. [19])

\begin{tabular}{lll}
\hline & HY-P & HY-M \\
\hline $\mathrm{Al}_{\text {tetrahedral }}\left({ }^{29} \mathrm{Si} \mathrm{NMR}\right)\left(\mathrm{mol} \mathrm{g}^{-1}\right)$ & $2.0 \cdot 10^{-3}$ & $2.1 \cdot 10^{-3}$ \\
$\mathrm{NH}_{3}$ chemisorbed $\left(\mathrm{mol} \mathrm{g}{ }^{-1}\right)$ & $6.6 \cdot 10^{-4}$ & $1.2 \cdot 10^{-3}$ \\
$\quad$ (corresponds to conc. of strong Brønsted acid sites) & & not det. \\
$\begin{array}{l}\text { Pyridine chemisorbed (mol g } \\
\quad(\text { corresponds to conc. of strong Brønsted acid sites) }\end{array}$ & $6.0 \cdot 10^{-4}$ & 142 \\
$\Delta \mathrm{H}_{\text {ads }}-\mathrm{NH} 3\left(\mathrm{~kJ} \mathrm{~mol}{ }^{-1}\right)$ & 140 & 0.49 \\
Concentration EFAL $\left(v_{\mathrm{OH}}=3617 \mathrm{~cm}^{-1}\right)$ (arb. units) & 1.04 & \\
\hline
\end{tabular}

but an identical concentration of tetrahedrally coordinated $\mathrm{Al}^{3+}$ in the zeolite lattice.

\subsection{Catalytic conversion experiments}

Experiments were carried out in a tubular flow reactor with an inner diameter of $5 \mathrm{~mm}$, operated under stationary differential conditions between $733 \mathrm{~K}$ and $813 \mathrm{~K}$. Typical catalyst weights varied from 5 to $50 \mathrm{mg}$. The samples were diluted with quartz to minimize the pressure drop across the catalyst bed (the catalyst particle size was approx. $1 \mu \mathrm{m}$ ). The catalyst was activated in a stream of air by increasing the temperature to $393 \mathrm{~K}(5 \mathrm{~K} / \mathrm{min})$ and holding that temperature for $30 \mathrm{~min}$. Then, the temperature was raised to $853 \mathrm{~K}(10 \mathrm{~K} / \mathrm{min})$ and kept at this level for one hour. After activation, the catalyst was cooled to reaction temperature in $\mathrm{He}$.

10 vol\% propane, 2 vol\% n-butane or 5 vol\% i-butane were used premixed with $\mathrm{He}$. n-Pentane was added to carrier gas $(\mathrm{He})$ via a syringe pump. The partial pressures of the hydrocarbons were varied from 0.01 to $10 \mathrm{kPa}$. After 30 minutes time on stream, the first data point was taken. Pressure transient response experiments were carried out by switching from $\mathrm{He}$ to a stream of $\mathrm{He}$ containing the reactant.

The products were stored in multiposition valves, separated by means of gas chromatography $\left(\mathrm{Al}_{2} \mathrm{O}_{3} / \mathrm{KCl}\right.$ capillary column $)$ and analyzed by a flame ionization detector and a mass spectrometer. The absence of thermal cracking was confirmed by blank experiments. The calculation of the rates of product formation and the experimental setup are described in detail in Refs. [21,22].

\section{Results and discussion}

\subsection{Conversion of normal alkanes}

The concentration of Brønsted acid sites, the rates and the turnover frequencies of propane, n-butane and n-pentane cracking at $773 \mathrm{~K}$ are compiled in 
Table 2

Conversion of propane, n-butane and n-pentane on H-FAU zeolites at $773 \mathrm{~K}$

\begin{tabular}{lll}
\hline & HY-P & HY-M \\
\hline Brønsted acid sites $\left(\mathrm{mol} \mathrm{g}^{-1}\right)$ & $6.6 \cdot 10^{-4}$ & $1.2 \cdot 10^{-3}$ \\
Propane & & \\
$\quad r_{\text {cracking }}\left(\mathrm{mol} \mathrm{g}^{-1} \mathrm{~s}^{-1} \mathrm{mbar}^{-1}\right.$ & $3.3 \cdot 10^{-10}$ & $5.4 \cdot 10^{-10}$ \\
$\mathrm{TOF}_{\text {cracking }}\left(\mathrm{molecules} \mathrm{site}^{-1} \mathrm{~s}^{-1} \mathrm{mbar}^{-1}\right)$ & $5.0 \cdot 10^{-7}$ & $4.5 \cdot 10^{-7}$ \\
$\mathrm{n}-$ Butane & & \\
$r_{\text {cracking }}\left(\mathrm{mol} \mathrm{g}^{-1} \mathrm{~s}^{-1} \mathrm{mbar}^{-1}\right)$ & $2.6 \cdot 10^{-9}$ & $4.2 \cdot 10^{-9}$ \\
TOF $_{\text {cracking }}\left(\mathrm{molecules} \mathrm{site}^{-1} \mathrm{~s}^{-1} \mathrm{mbar}^{-1}\right)$ & $4.0 \cdot 10^{-6}$ & $3.5 \cdot 10^{-6}$ \\
$\mathrm{n}-$ Pentane & & \\
$r_{\text {cracking }}\left(\mathrm{mol} \mathrm{g} \mathrm{s}^{-1} \mathrm{mbar}^{-1}\right)$ & $2.3 \cdot 10^{-8}$ & $4.2 \cdot 10^{-8}$ \\
TOF $_{\text {cracking }}\left(\mathrm{molecules} \mathrm{site}^{-1} \mathrm{~s}^{-1} \mathrm{mbar}^{-1}\right)$ & $3.5 \cdot 10^{-5}$ & $3.5 \cdot 10^{-5}$ \\
\hline
\end{tabular}

Table 2. The two samples did not differ in the strength of the Brønsted acid sites as seen from the heats of adsorption of ammonia (Table 1). Turnover frequencies correspond to the rates normalized to the concentration of the strong Brønsted acid sites determined by ammonia t.p.d.. Protolytic cracking was used for comparison, because it was expected not to be strongly influenced by secondary processes. Since the overall rates decreased with increasing conversion for $\mathrm{n}$-butane and $\mathrm{n}$-pentane, the rates shown in Table 2 were obtained by extrapolation to zero conversion for both samples.

Fig. 1 shows the dependence of the logarithm of the rate of protolytic cracking vs. the carbon number of the converted alkane. For both zeolite catalysts, the logarithm of the rate increased linearly with the size of the alkane. As these lines are parallel, the apparent rate constant, which is at low alkane

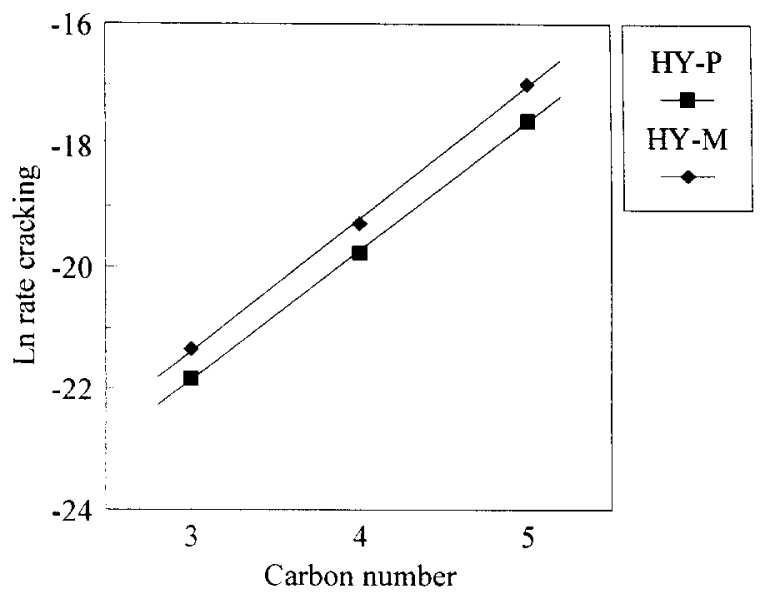

Fig. 1. Conversion of propane, n-butane and n-pentane on HY-M and HY-P at $773 \mathrm{~K}$. Logarithm of the rate vs. carbon number. 


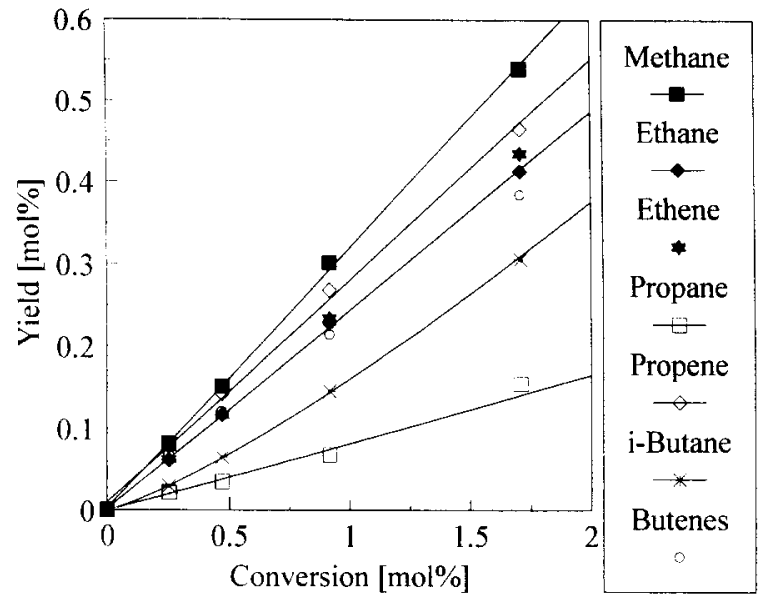

Fig. 2. Conversion of n-butane on HY-M at $733 \mathrm{~K}$. Product yield vs. conversion.

coverages a product of the rate constant and the adsorption constant, vary in a constant manner, i.e., with an incrementing factor of 8 to 10 per C-atom. Considering that the sorption constant in HFAU varies from 0.016 to 0.74 mbar $^{-1}$ (incrementing factor of 7 per C-atom) we conclude that the reaction constant does not vary with the size of the hydrocarbon. A similar conclusion has been reached previously for cracking of light alkanes over H-ZSM5 [21].

The conversion of propane yielded methane, ethene and propene as primary products on both catalysts as concluded from the positive initial slopes in the corresponding yield vs. conversion plots. Methane and ethene were formed in equimolar amounts. Other products were only detected in trace amounts. Thus, the conversion of propane can be quantitatively explained by protolytic cleavage of $\mathrm{C}-\mathrm{C}$ or $\mathrm{C}-\mathrm{H}$ bonds. The selectivity to dehydrogenation was higher on the parent than on the modified faujasite. The turnover frequencies and the apparent energies of activation ( $165 \mathrm{~kJ} / \mathrm{mol}$ ) for cracking (Table 2) were identical for both catalysts suggesting that Brønsted acid sites are solely responsible for protolytic cracking.

The conversion of n-butane yielded methane and propene, ethane and ethene, and butenes as primary products for both catalysts (see Fig. 2). The selectivity was higher to methane than to ethane. Both selectivities, however, were independent of the temperature indicating identical apparent energies of activation. Additionally, some propane and i-butane was detected. iso-Butane is formed in an apparent primary reaction indicating that butylcarbeniuim ions formed do not leave the surface during the isomerization and hydride transfer reactions. A smaller amount is also formed via classical secondary reaction pathways. As in the case of propane, the selectivity to dehydrogenation was lower on HY-M compared to HY-P. The turnover frequencies for n-butane cracking were again identical for both samples (see Table 2). 
A similar behavior was also observed for the conversion of n-pentane on both catalysts. Methane and ethane were concluded to be formed via protolytic cracking. Propane originates from protolytic cracking and from secondary (bimolecular) hydride transfer. The selectivities to methane and ethane were approximately identical. Both values were higher than the initial selectivity to propane.

As reported earlier for H-ZSM5 [21,22] the selectivities to methane and ethane on HY-P and HY-M did not change as a function of temperature suggesting identical energies of activation for protolysis. The selectivity to butene was lower than that to methane. This indicates that butenes are consumed by hydride transfer or other secondary reactions. Note that the rates to i-butane, n-butane (produced from butenes by hydride transfer) and to the butenes add up to a value which only slightly exceeds the rate of methane formation. The rate of dehydrogenation was again higher on HY-P than on HY-M. As for all other n-alkane conversions identical turnover frequencies for protolytic cracking were

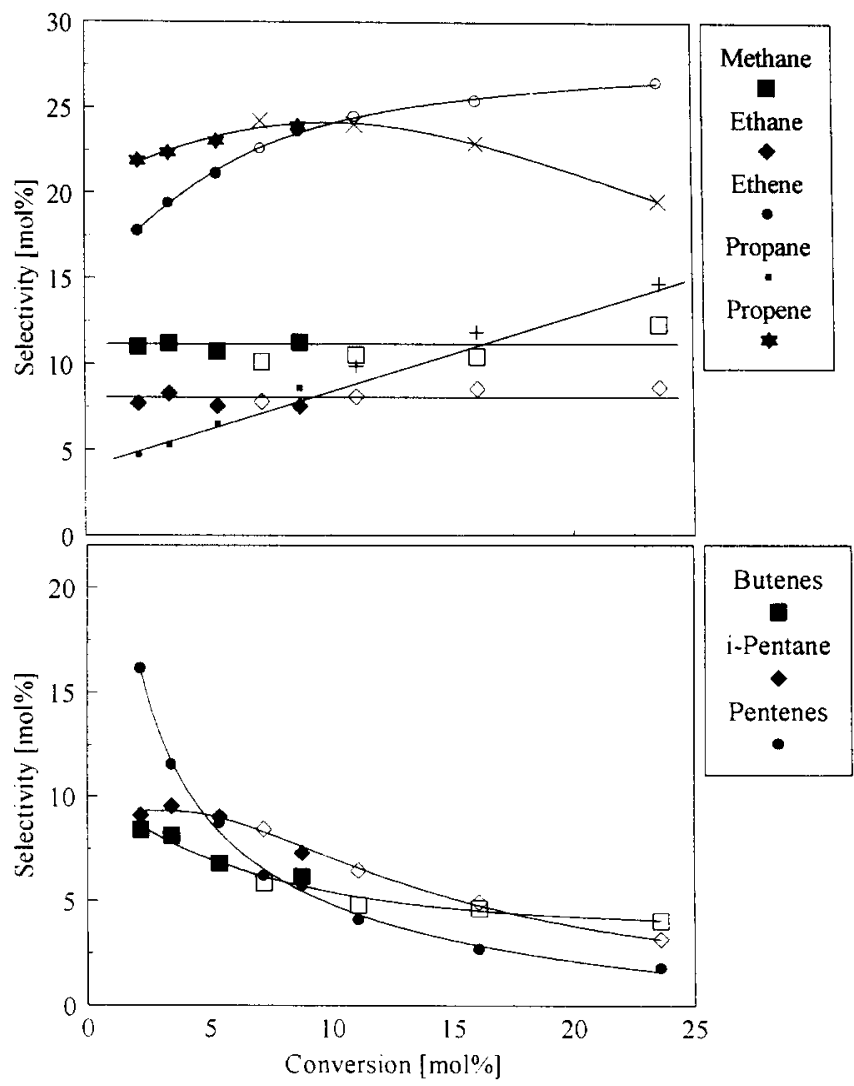

Fig. 3. Comparison of the product selectivities for the conversion of n-pentane on HY-P and HY-M at $813 \mathrm{~K}$. Closed and open symbols refer to the parent and the modified faujasite, respectively. 
observed for both faujasite samples. Thus, we conclude that only the Brønsted acid sites are active for cracking, and that the catalytic activity of the Brønsted acid sites is not altered by the presence of cationic extraframework aluminium.

The identical intrinsic properties of the acid sites in both samples are also reflected by the identical selectivities for primary and secondary products on both catalysts provided the overall conversion was the same (see Fig. 3). At all temperatures investigated, the changes in selectivity with increasing conversion were independent of the catalyst used. Thus, we conclude that selectivity only depends on the overall conversion and is not a function of the concentration of the extralattice material. This implies identical interaction of hydrocarbons with both samples, i.e., the hydrocarbons have the same heats of adsorption and adsorption constants on both zeolites. Changing reaction conditions to induce higher conversion and then returning to the original conditions led to completely reversible changes in terms of selectivities and activities. This implies that the lower turnover frequencies at higher conversions are not the result of site
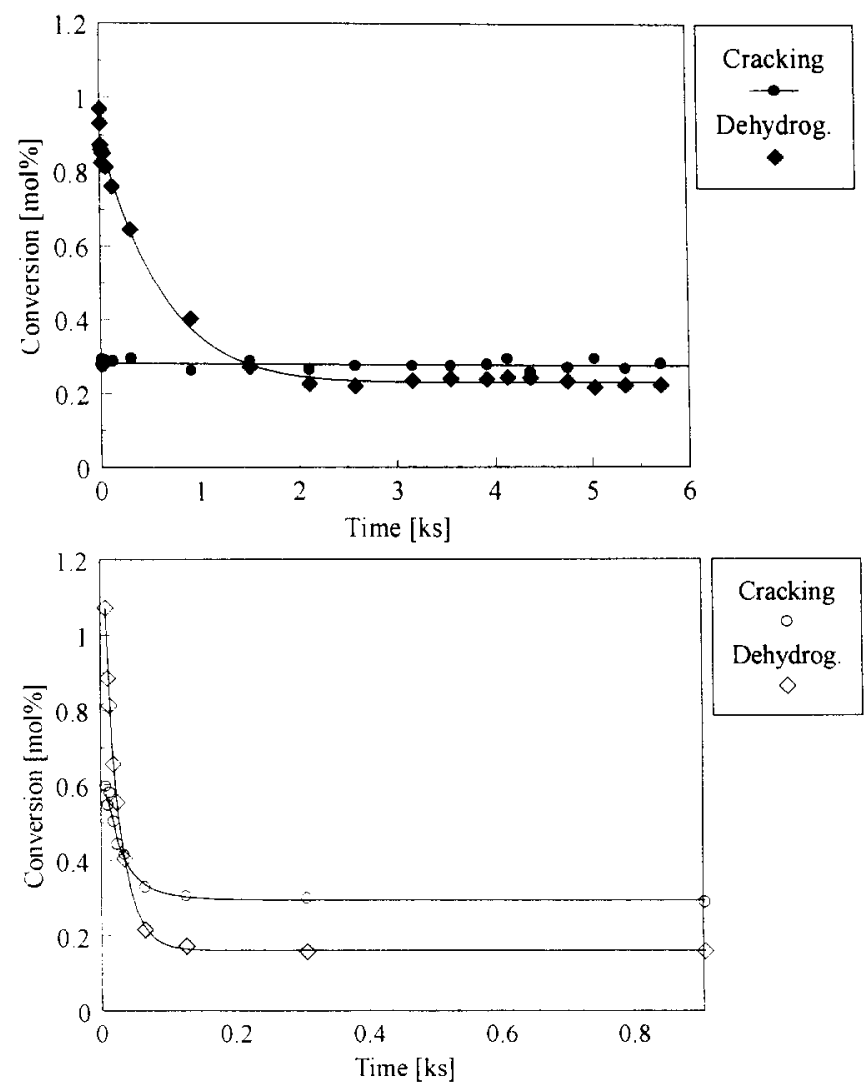

Fig. 4. Pressure transient response experiment of n-butane on HY-P and HY-M at $733 \mathrm{~K}$ (inc. $p_{\text {Butane }} 0 \rightarrow 4$ $\mathrm{kPa}$ ). Closed and open symbols refer to the parent and the modified faujasite, respectively. 
blocking because of coking, but rather the result of reversible site occupation (sites which are temporarily not available for protolytic conversion of the alkane) by strongly adsorbed olefins. The very small amount of coke on the catalysts after reaction, as detected by temperature programmed oxidation, confirm this model.

For both catalysts high initial activity to dehydrogenation was observed, which decreased with time on stream (see Fig. 4) and reached a steady state. However, the value was higher on the modified (HY-M) than on the parent (HY-P) sample. Also, the decay of dehydrogenation activity was significantly slower for HY-P (approx. 30min) than the decay observed with HY-M (approx. $5 \mathrm{~min}$ ). This suggests that extra-framework species play a major role for the dehydrogenation at short times on stream. Note, that a decay in the initial dehydrogenation activity with the first 5 minutes time on stream was also observed with H-ZSM5 [22]. That decrease in dehydrogenation activity was shown not to be the result of deactivation by coking, but rather to be due to a reversible blocking of a second dehydrogenation pathway due to slow hydrogen desorption [22].

\subsection{Conversion of $i$-butane}

Table 3 shows the comparison between the conversion of n-butane and i-butane on HY-P and HY-M at $773 \mathrm{~K}$. The product selectivities are depicted in Fig. 5 for HY-M at $773 \mathrm{~K}$. Methane and propene were formed in equimolar

Table 3

Comparison of the rates of cracking and dehydrogenation of n-butane and i-butane over faujasites at $733 \mathrm{~K}$

\begin{tabular}{|c|c|c|c|c|}
\hline & \multicolumn{2}{|c|}{ i-Butane } & \multicolumn{2}{|c|}{ n-Butane } \\
\hline & HY-M & HY-P & HY-M & HY-P \\
\hline$r$ (Methane) $\cdot 10^{9}\left(\mathrm{~mol} \mathrm{~g}^{-1} \mathrm{~s}^{-1} \mathrm{mbar}^{-1}\right)$ & 6.8 & 5.5 & 2.3 & 1.4 \\
\hline$r($ Ethane $) \cdot 10^{9}\left(\mathrm{~mol} \mathrm{~g}^{-1} \mathrm{~s}^{-1} \mathrm{mbar}^{-1}\right)$ & - & - & 1.7 & 1.0 \\
\hline$r$ (Ethene) $\cdot 10^{9}\left(\mathrm{~mol} \mathrm{~g}^{-1} \mathrm{~s}^{-1} \mathrm{mbar}^{-1}\right)$ & 0.1 & 0.1 & 1.8 & 1.1 \\
\hline$r$ (Propane) $\cdot 10^{9}\left(\mathrm{~mol} \mathrm{~g}^{-1} \mathrm{~s}^{-1}\right.$ mbar $\left.^{-1}\right)$ & 0.3 & 1.3 & 0.5 & 0.2 \\
\hline$r$ (Propene) $\cdot 10^{9}\left(\mathrm{~mol} \mathrm{~g}^{-1} \mathrm{~s}^{-1} \mathrm{mbar}^{-1}\right)$ & 6.4 & 5.2 & 2.1 & 1.3 \\
\hline$r(\mathrm{i}-$ Butane $) \cdot 10^{9}\left(\mathrm{~mol} \mathrm{~g}^{-1} \mathrm{~s}^{-1} \mathrm{mbar}^{-1}\right)$ & feed & feed & 1.0 & 0.5 \\
\hline$r($ n-Butane $) \cdot 10^{9}\left(\mathrm{~mol} \mathrm{~g}^{-1} \mathrm{~s}^{-1} \mathrm{mbar}^{-1}\right)$ & 1.7 & 1.1 & feed & feed \\
\hline$r(\Sigma$ Butenes $) \cdot 10^{9}\left(\mathrm{~mol} \mathrm{~g}^{-1} \mathrm{~s}^{-1} \mathrm{mbar}^{-1}\right)$ & 13 & 10 & 1.7 & 1.4 \\
\hline$r_{\text {cracking }} \cdot 10^{9}\left(\mathrm{~mol} \mathrm{~g}^{-1} \mathrm{~s}^{-1} \mathrm{mbar}^{-1}\right)$ & 6.8 & 5.5 & 4.0 & 2.4 \\
\hline$r_{\text {dehydrogen }} \cdot 10^{9}\left(\mathrm{~mol} \mathrm{~g}^{-1} \mathrm{~s}^{-1} \mathrm{mbar}^{-1}\right)$ & 15 & 11 & 2.7 & 1.9 \\
\hline$\sum r \cdot 10^{9}\left(\mathrm{~mol} \mathrm{~g}^{-1} \mathrm{~s}^{-1} \mathrm{mbar}^{-1}\right)$ & 22 & 17 & 6.7 & 4.3 \\
\hline$r_{\text {C-balance }} \cdot 10^{9}\left(\mathrm{~mol} \mathrm{~g}^{-1} \mathrm{~s}^{-1} \mathrm{mbar}^{-1}\right)$ & 22 & 17 & 7.2 & 4.4 \\
\hline $\mathrm{TOF}_{\text {cracking }} \cdot 10^{6}$ (molecules site ${ }^{-1} \mathrm{~s}^{-1}$ mbar $^{-1}$ ) & 5.7 & 8.3 & 3.3 & 3.6 \\
\hline $\operatorname{TOF}_{\Sigma} \cdot 10^{6}$ (molecules site $\left.{ }^{-1} \mathrm{~s}^{-1} \mathrm{mbar}^{-1}\right)$ & 18 & 25 & 5.6 & 6.5 \\
\hline$r_{\text {cracking }} / r_{\text {dehydrogen }}$ & 0.5 & 0.5 & 1.5 & 1.3 \\
\hline$E_{\mathrm{A} \text { cracking }}\left(\mathrm{kJ} \mathrm{mol}^{-1}\right)$ & 155 & 155 & 140 & not det. \\
\hline$E_{\mathrm{A} \text { dehydrogen }}\left(\mathrm{kJ} \mathrm{mol}^{-1}\right)$ & 155 & 155 & 140 & not det. \\
\hline
\end{tabular}




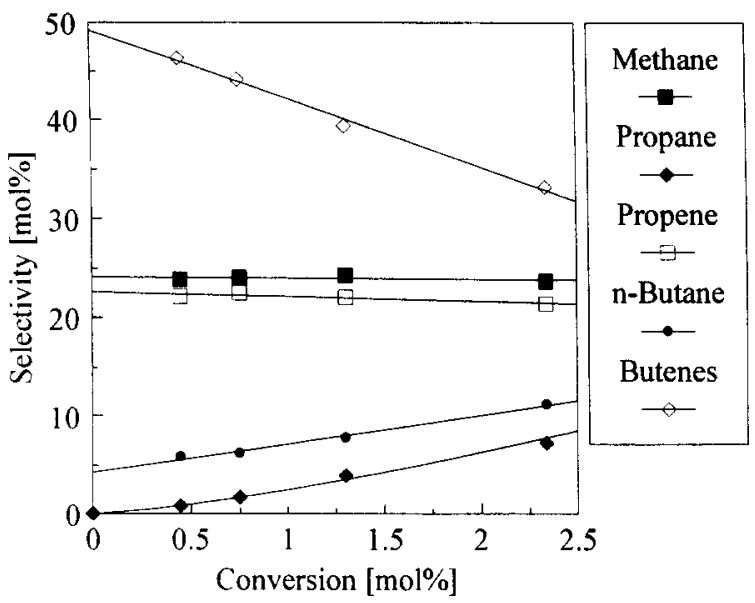

Fig. 5. Conversion of iso-butane on HY-M at $773 \mathrm{~K}$. Selectivity vs. conversion.

amounts. Together with the butene isomers both products were concluded to be formed in primary reactions. On both faujasite samples initially the rate of dehydrogenation exceeded the rates to all other products. With increasing conversion, however, the butenes were consumed forming n-butane and propane via hydride transfer. Additionally, at high conversions, ethene was observed in small amounts indicating secondary monomolecular cracking of butenes. Note that ethane was never detected suggesting that monomolecular isomerization of the i-butylcarbonium ion followed by cracking can be excluded to occur.

The total rate of i-butane conversion on HY-M was three times higher than that of n-butane. This was caused by the drastical increase in the rate of dehydrogenation and also by the more moderate increase in the rate of cracking. Note that this clearly contrasts the results obtained for H-ZSM5, where the total rates were identical for the conversion of linear and branched hydrocarbons [22]. Two explanations are suggested, i.e., (i) extraframework alumina contributes directly or indirectly to the activation of the i-alkane over faujasites or (ii) i-alkane conversion over H-ZSM5 is constrained by means of steric hindrance. Support for this latter argument is seen in the heat of sorption of the alkanes, which is some $6-8 \mathrm{~kJ} / \mathrm{mol}$ lower for iso-alkanes than for n-alkanes on H-ZSM5, but equal or slightly higher on H-FAU and H-MOR [23].

\section{Conclusions}

The present results demonstrate that extraframework aluminum does not influence the intrinsic rates (TOF) of carbon-carbon bond cleavage of light linear and branched alkanes over faujasites. Thus, for cracking, the major effect of extraframework alumina in the samples studied is the reduction of the 
concentration of strong Brønsted acid sites by acting as cationic species. Removal of these moieties frees a larger fraction of Brønsted sites and leads, thus, to a higher catalytic activity. The intrinsic properties of the Brønsted sites remain unchanged.

The rates of protolytic alkane conversion are largely determined by the amount of unoccupied Brønsted acid sites. At high dehydrogenation rates strong olefin adsorption temporarily blocks these sites for the protolytic conversion and enhances secondary processes. This explains the decreasing overall activity and the variation in the product selectivities with increasing conversion. By repeated variation of the conversion we could exclude coking as the cause of the decrease of activity.

In contrast to cracking, the rates of dehydrogenation were generally higher at the initial stages of the reaction than at steady state and higher in the presence of EFAL than in its absence. In accordance with earlier findings, the high activity to dehydrogenation at inital stages of the reaction is concluded to be due to a separate reaction pathway which does not contribute to the catalytic activity at steady state. Nevertheless, extraframework aluminum oxide species seem to enhance the activity to cracking and dehydrogenation for iso-alkanes at steady state, which is suggested to be the result of altered reactant sorption properties or subtle changes in the acid/base properties not monitored by the heat of sorption of n-alkanes.

\section{Acknowledgements}

Financial support by the Christian Doppler Laboratory for Heterogeneous Catalysis is gratefully acknowledged.

\section{References}

[1] J. Ward, Adv. Chem., 101 (1970) 380.

[2] H.A. Benesi and B.H.C. Winquist, Adv. Catal., 27 (1978) 97.

[3] D. Barthomeuf, Stud. Surf. Sci. Catal., 65 (1991) 157.

[4] D.T. Chen and J.A. Dumesic, Catal. Lett., 12 (1992) 201.

[5] A. Aroux, Y.S. Yin and J.C. Vedrine, Appl. Catal., 36 (1988) 323.

[6] D.H. Olson, R.M. Lago and W.O. Haag, J. Catal., 61 (1980) 390.

[7] W.O. Haag, R.M. Lago and P.B. Weisz, Nature, 309 (1984) 589.

[8] H.A. Bencsi, J. Catal., 8 (1967) 368.

[9] P.B. Venuto, L.A. Hamilton, P.S. Landis and J.J. Wise, J. Catal., 4 (1966) 81.

[10] D. Barthomeuf, J. Phys. Chem., 83 (1979) 249.

[11] R. Beaumont and D. Barthomeuf, J. Catal., 26 (1972) 218.

[12] B. Beagley, J. Dwyer, F.R. Fitch, R. Mann and J. Walters, J. Phys. Chem., 88 (1984) 1744.

[13] R.M. Lago, W.O. Haag, R.J. Mikovsky, D.H. Olson, S.D. Hellring, K.D. Schmitt and G.T. Kerr, Stud. Surf. Sci. Catal., 28 (1986) 677.

[14] E.A. Lombardo, G.A. Sill and W.K. Hall, J. Catal., 119 (1989) 426. 
[15] G.J. Kramer, R.A. van Santen, C.A. Emeis and A.K. Nowak, Nature, 363 (1993) 529.

[16] R.A. Beyerlein, G.B. McVicker, L.N. Yacullo and J.J. Ziemiak, J. Phys. Chem., 92 (1988) 1967.

[17] J.R. Sohn, S.J. DeCanio, P.O. Fritz and J.H. Lunsford, J. Phys. Chem., 90 (1986) 4847.

[18] F. Lonyi and J.H. Lunsford, J. Catal., 136 (1992) 566.

[19] M. Stockenhuber, PhD Thesis, 1994, Technical University of Vienna, Vienna, Austria.

[20] M. Stockenhuber and J.A. Lercher, Microporous Mater., 3 (1995) 457.

[21] T.F. Narbeshuber, H. Vinek and J.A. Lercher, J. Catal., 157 (1995) 388.

[22] T.F. Narbeshuber, PhD Thesis, 1994, University of Twente, Enschede, The Netherlands, ISBN: 909007754-5.

[23] F. Eder, M. Stockenhuber and J.A. Lercher, submitted for publication. 